\title{
NDT Based Process Monitoring and Control
}

\author{
Bernd Wolter* - Gerd Dobmann - Christian Boller \\ Fraunhofer Institute for Non-Destructive Testing (IZFP), Germany
}

\begin{abstract}
The old focus on using automation was simply to increase productivity and reduce costs. Today, the purpose of automation has shifted to broader issues. Highly automated processes ensure high quality on a constant level, if it is connected with a high degree of (automated) monitoring and control. Meanwhile, continuous process and quality monitoring by non-destructive testing (NDT) is an accepted procedure to early diagnosis of irregular process conditions, followed by an NDT-based feed back control and optimization. Consequently, the development of process integrated NDT is an important scientific task. Such developments have to fulfil the requirements of today's industrial production concerning integrability, automation, speed, reliability and profitability. Flat steel production and processing, gas assisted injection moulding and cold joining processes are some examples of a successful application of the process integrated NDT.
\end{abstract}

(C)2011 Journal of Mechanical Engineering. All rights reserved.

Keywords: automation, mechanical material properties, micro-magnetic method, microwaves, nondestructive testing (NDT), process integrated NDT, process control, process monitoring, residual stress, tool-integrated sensor, ultrasound

\section{INTRODUCTION}

Automation was developed in order to avoid hazardous or unpleasant manual operations and to increase productivity. On the other hand, automation should also be considered as a social issue since the early days of industrialization because manual labour was replaced with lessexpensive machines. Today, automation of the workforce is quite advanced and is encroaching on ever more skilled jobs.

If the old focus on using automation was simply to increase productivity and reduce costs, currently the purpose of automation has shifted to broader issues. Automation is now often applied primarily to increase quality in the manufacturing process. By replacing manual work with an automated process, error rates can be reduced drastically. Even if automation is viewed as a way to minimize human error in a system, increasing the degree and levels of automation also increases the consequences of error. With increasing levels of automation the consequences of an error rapidly approach a catastrophe. It is for this reason that a high degree of process automation requires a high degree of (automated) monitoring and control of process and product quality.

Currently, the manufacturing industry is facing significant new challenges. Competitive producers have to be able to offer a broad range of products with specific, custom-tailored technological properties in a short time. This requires an increasing number of production processes of high complexity. Reduced development times and increased diversity of products and processes also means that there is less time to ensure that the manufacturing processes is capable of producing appropriate product quality before high-volume production starts. Nevertheless, manufacturers are becoming less vertically integrated and increasingly rely on external suppliers even with highly sophisticated parts and components. These new challenges of automated manufacturing result in a steadily increasing need for non-destructive testing (NDT), which as an integrated component of the process, allows its continuous monitoring and qualitybased control.

Meanwhile, a variety of examples for in-process NDT can be found in beam welding processes. In case of laser beam welding, optical sensors are used to adaptively control the focus position and laser power by monitoring the weld seam line and its geometry or the light reflected from the weld seem. For example, Kaierle et al. [1] have proposed such an on-line quality control scheme. More sophisticated NDT, like laser-ultrasound and acoustic emission allow to determine penetration depth and to detect weld seam errors in real time, as proposed by Satoru 
[2]. The use of tool-integrated ultrasound and acoustic emission for endpoint control and process optimization during resistance spot welding was reported from several authors, for example from Waschkies [3] and Dennison et al. [4]. Schneider et al. [5] have used tool-integrated ultrasound for end-point control during the screw driving (see section 3.3). Acoustic emission is also well known as a tool for detecting tool wear and break and other irregular process conditions during machining process, as for example reported from Guo and Ammula [6] or Chen and Griffin [7]. In order to determine variations of mechanical properties or residual stress during machining, micro-magnetic sensors can be used, which are integrated into the machining tool, as proposed by Wolter et al. [8]. As described in section 3.1, another application of micro-magnetic methods is the monitoring of quality characteristics in flat steel products during producing and processing (Altpeter et al. [9], Dobmann et al. [10], Wolter et al. [11]). Other NDT methods are needed if the processing of non-metallic materials, like polymers should be monitored and controlled. An example, reported by Sklarczyk et al. [12] will be described in section 3.2.

\section{BENEFITS FROM NDT BASED PROCESS MONITORING AND CONTROL}

In addition to the final inspection of products, NDT can be used during manufacturing in terms of monitoring and even control of process quality, as described in Fig. 1. Quality control with
NDT combines the advantages of both classical methods of process control, which are statistical process control (SPC) on the one hand and monitoring of process variables on the other. The intent of SPC is to monitor product quality and maintain processes to fixed targets. It aims to get and keep processes under control. However, - due to its probabilistic nature - SPC can keep a process under control only to the extent that it can indicate when a process might have gone out of control. Therefore, process readjustments or repairs are always delayed.

In principle, a continuous preservation of process quality is not possible with SPC. Another approach is the real-time model-based quality control by monitoring of process measurable (force, pressure, temperature, etc.). A process disturbance can be identified and based on a known control model and the process can be readjusted or adapted immediately although the real-time quality feedback to this disturbance is lacking. An additional quality model is necessary, in order to determine to what extent quality has been affected.

Automated NDT is capable of performing all SPC functions in real-time or at least several times faster than standard SPC. As a monitoring tool, it allows to mark and discard all nonconforming parts. Only good material goes "out the back door". Consequently, the process limits can be exhausted, allowing increased productivity.

On the other hand, process disturbances affecting the product quality can be detected and

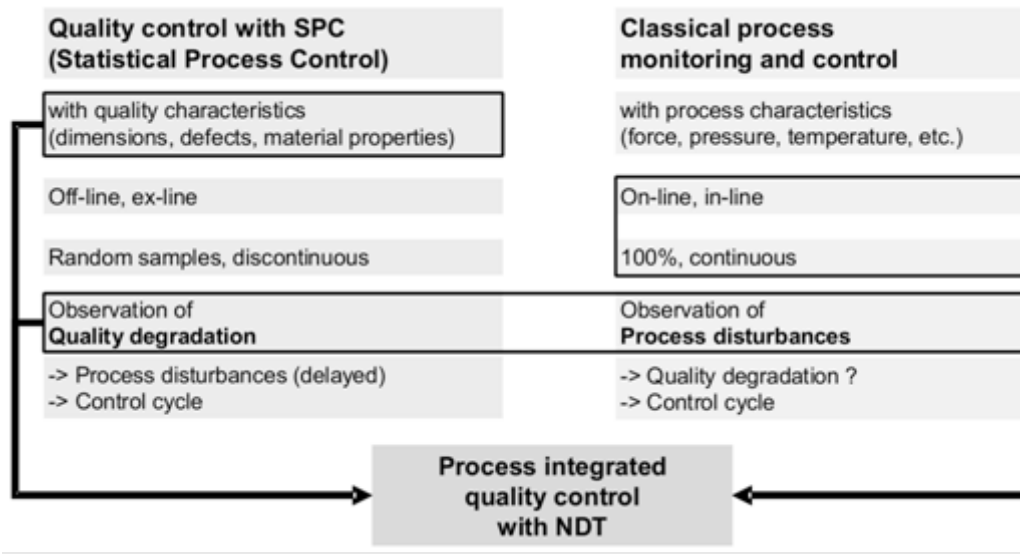

Fig. 1. Quality control with NDT 
located directly. The process can be controlled using its quality characteristics as control variables directly.

\section{REQUIREMENTS FOR PROCESS INTEGRATED NDT}

Process-integrated NDT has to meet a variety of requirements. Customers ask for NDT systems, which are integrable, automatable, realtime capable, reliable, profitable and flexible.

\subsection{Integrable, Mountable}

Miniaturized, rugged, low-maintenance NDT sensors at moderate costs are required. An example is described in section 3.2 and was presented by Sklarczyk et al. [12]. As a further example, Kloster et al. [13] have shown that GMR (giant magneto-resistance) gradiometers allow to design very compact stray flux sensors with integrated pre-magnetization device. Dobmann [14] has reported that the general trend for process sensors evolving from simple analogous measuring recorders to the so-called "smart sensors" or "intelligent sensors" with integrated signal processing or even with integrated actuator will be transferred to NDT sensors too. Bräuer et al. [15] have used thin-film technology to integrate temperature or force sensors as a "sensitive skin" on the surface of a machine or a tool.

It is expected that the combination of thinfilm technology with other physical measurement effects permits the development of new toolintegrated NDT sensors. The communication with process integrated NDT systems has to account for established industrial interface standards. Industrial process control systems commonly make use of field-buses, which are specialized for the process control environment (Profi-bus, LonTalk, SDS, etc.).

\subsection{Automatable}

For most manufacturing processes the degree of automation is permanently increasing. The vision of an "autonomous production" includes the idea that all desired tasks can be performed without or at least with a minimum human interaction. This is true also for tasks of quality monitoring and control. Therefore, not only sophisticated mechatronical layouts for sensor and / or part manipulation have to be developed, but also intelligent concepts for automated acquisition, evaluation, transfer and management of inspection data, right up to autonomous procedures for selfcalibration and self-maintenance.

\subsection{Real-Time Capable}

For a variety of NDT techniques (e.g. micro-magnetic methods, nuclear magnetic resonance - NMR) the inspection speed is limited by physical constraints. With these methods, only relatively slow processes can be monitored in realtime. Often not only a slow data acquisition rate, but also the subsequent data processing is limiting the testing rate. Especially in case of fast image reconstruction, evaluation and presentation, fast transfer and computation of the raw measuring data is required. "Multi-Link G-bit Ethernet", "Routed Fiber-channel Link", or "Multi-channel LVDS" are non-standard solutions for fast data transfer. Sophisticated data processing algorithms as well as fast devices for parallel computing like Graphics Processing Units (GPU) and Field Programmable Gate Arrays (FPGA). Such approaches have been used for NDT systems since Bulavinov et al. [16].

\subsection{Reliable and Comprehensive}

The integrated NDT technique has to provide the measurable with reliability, which is predetermined by the quality requirements of the process, which means that the NDT technique itself has to meet the criteria of measuring gauge capability standards in order to monitor and control the quality capability of the process. In order to achieve a required process capability index CP, the NDT measurement uncertainty must not exceed a defined percentage of the process tolerance range. In some cases a single NDT method is not sufficient to acquire all relevant quality information of the process with the obligatory measuring uncertainty. Therefore, the trend can be recognized to combine several NDT methods with partly divers and partly redundant information. 

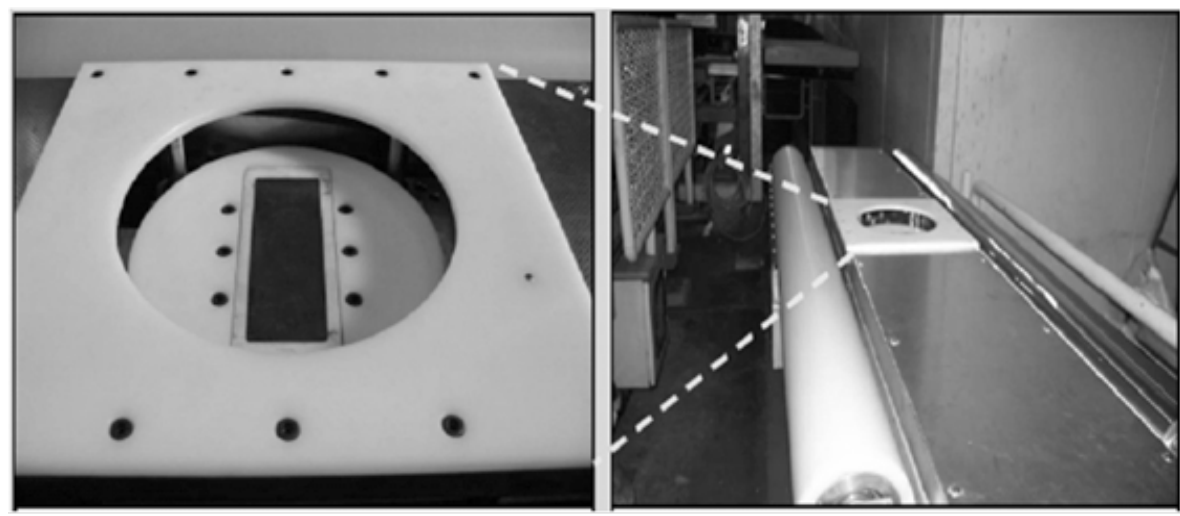

Fig. 2. Sensor holder and table carrier of the micro-magnetic in-line inspection system

\subsection{Profitable and Flexible}

Nondestructive testing systems are not mass-produced products. The small number of marketable systems and the specifics of individual test requirements lead to high engineering expenditures at low sales volumes. Especially process integrated NDT systems are often "unique items", leading to high costs for purchase and maintenance. However, these costs are faced with a variety of savings, which are often overlooked. These include not only the saved non-conformity costs (costs due to further processing, eliminating the nonconforming material, call-back, product liability, etc.) but also the saved costs for manual tests (destructive and nondestructive) and the possibility to increase productivity and yield.

On the other hand, ways have to be found to reduce the engineering expenditures for highly sophisticated NDT systems. As claimed by Kroening et al. [17], flexible, cost-effective solutions for NDT hardware and software could be developed based on modular structured platforms, which support a further development of a preferably large field of individual NDT techniques.

\section{CASE STUDIES}

\subsection{Quality Control in Flat Steel Production and Processing}

The mechanical-technological properties characterize the fitness for use of a material under various conditions. In addition to thickness, width, surface finish and flatness, these properties are of central importance to the quality of hot and cold rolled steel products. These material properties are adjusted during several production steps. Therefore, there is the need to monitor and control these quality parameters continuously. State of the art to determine yield and tensile strength is the selection of standardized specimens at the end of the process and destructive testing according to the definition in the inspection laboratory using standard tensile testing machines. Hardness measurements are performed by using standardized indentation techniques according to Brinell or Vickers.

This destructive testing is obviously not an adequate solution for online monitoring and control. The traditionally process orientated steel industry has a strong interest to replace these time-consuming and expensive destructive tests by more appropriate methods.

Micro-magnetic testing, i.e. nondestructive (ND) material characterization with electromagnetic methods is generally suited for this purpose. In a ferromagnetic steel mechanical and magnetic properties of are influenced by the same microstructural parameters (lattice defects).

Therefore, correlations between both, which can be used to predict values of mechanical properties from measured values of magnetic properties, can be observed. A technically mature application of micro-magnetic NDT is the inline monitoring of mechanical parameters in strip steel during production, as shown in Fig. 2. This application was described by Wolter and Dobmann in 2006. 
Another possibility is to attach the micromagnetic sensor to a robotic arm, as it is shown in Fig. 3 (Dobmann et al. [14]). This allows the maximum possible flexibility regarding the sensor application to the strip surface.

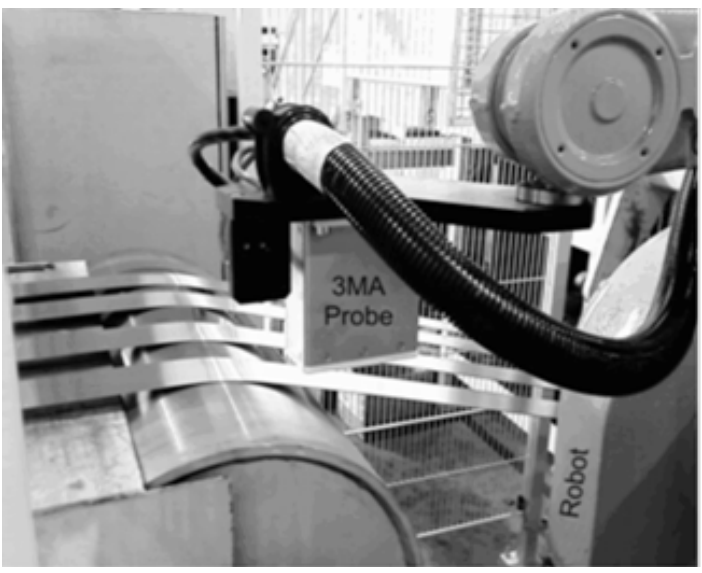

Fig. 3. Sensor attached to a robot for gradual inspection of several parallel running strips

Micro-magnetic testing can be used not only for monitoring and control during steel sheet production, but also during sheet processing, i.e. deep-drawing. Altpeter et al. [9] have developed a miniaturized sensor (see Fig. 4), which can be integrated into the stamp of a deep-drawing machine.
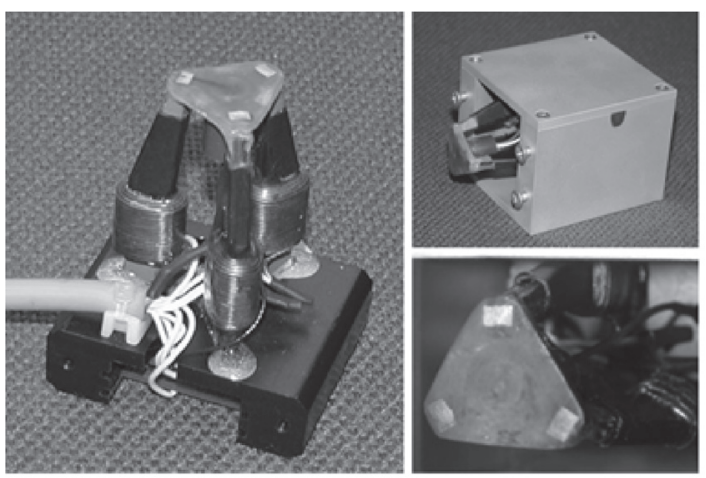

Fig. 4. Miniaturized micro-magnetic sensor, integratable into a deep-drawing stamp

With this tool, material behaviour during the deep-drawing process can be observed. It allows the modification of mechanical properties as well as the arising stresses and strains in the material to be monitored during the process.
Based on this method the manipulated variables of the process (stamp force, path, etc.) can be optimized for different conditions (sheet thickness, steel grade, etc.) and furthermore, it allows to prevent process malfunctions (rip-off, spring-back of the sheet) by a feed-back control based on the detected strain hardening in the material.
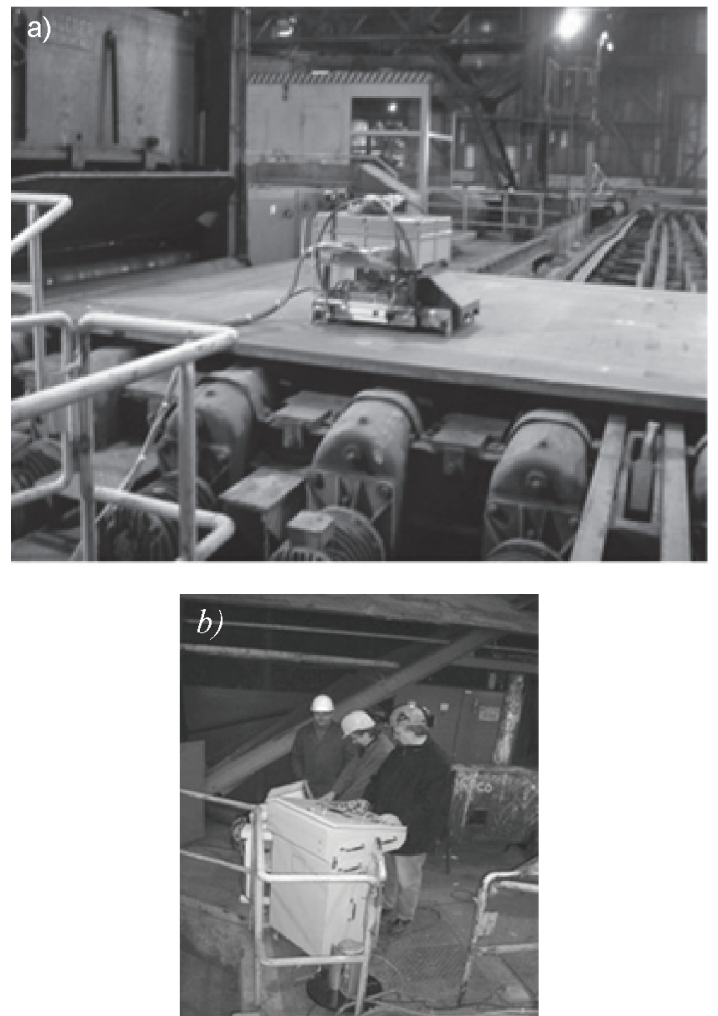

Fig. 5. Heavy plate inspection with micromagnetic techniques, a) inspection trolley, b) remote control desk

Mechanical-technological properties are also important for heavy plate production. The customer asks for geometrical and mechanical properties, which are uniform across product length and width, especially for high-value grades. For a plate with a length of several meters, the boarders are usually subjected to other cooling conditions than the rest. Indeed, especially the plate ends are known to cool faster, generating an undesired increase in $R_{m}$ and $R_{p 0.2}$. State-of-the-art is to determine this so-called "cold ends" based on empirical values and cut them off. The destructive 
testing of the cold ends follows this cutting. Therefore, the cutting itself is not a controlled process and if too much or to less material has been cut-off, this will only be realized in hindsight.

This lack of knowledge results in enormous costs due to reworking, pseudo-scrap and delayed shipment release. The European steel producers put their annual costs at 11 million Euros. For that reason an NDT solution to locate the cold ends of the plate was developed. Knowing exactly the contour of the zone with unacceptable material allows an open loop control for the cutting process.

It has been established that for determination of mechanical properties in highly texturized materials, it is beneficial to combine micro-magnetic methods with ultrasonic time-offlight measurements in order to get more accurate and reproducible results. The NDT equipment was integrated into a remote controlled trolley, allowing the sensor to be half-automatically moved along the surface of the plate (Wolter et al. [8]). The left picture in Fig. 5 shows the trolley in operation on a heavy plate on the roller conveyor and the right picture shows the control desk for remote control.

\subsection{Microwave Monitoring of Gas Assisted Injection Moulding}

The plastics industry has an increasing need for online monitoring of injection moulding processes. Gas-assisted processes (gas injection technique GIT) are applied to save plastics material and to assure the constancy of the shape of the produced part. The aim of the process monitoring and surveillance is to assure the proper sequence of process steps and the correct position of the gas bubble inside the cavity. Existing monitoring methods like the measurement of temperature or pressure inside the cavity provide only indirect information or are often not quick and specific enough with regard to gas-assisted processes.

As it has been reported by Sklarczyk et al. [12], Fraunhofer IZFP and ICT have developed a miniaturized GIT monitoring system based on the $94 \mathrm{GHz}$ radar sensor of Fraunhofer IAF (see Fig. $6)$.
In contrast to conventional microwave sensors, this module is capable of measuring not only amplitude but also phase and frequency. The entire size of this module is small enough to be mounted into the gas-assisted injection moulder. A high temperature resistant plastics window transparent to microwaves is used as a dielectric antenna and separates the cavity from the waveguide. Fig. 7a gives the scheme of the measurement arrangement. When the cavity is filled with liquid plastics and when a gas bubble passes over the position of the window the wave propagation inside the cavity is modified resulting in a measurable change of the reflection and scattering behaviour inside the cavity.
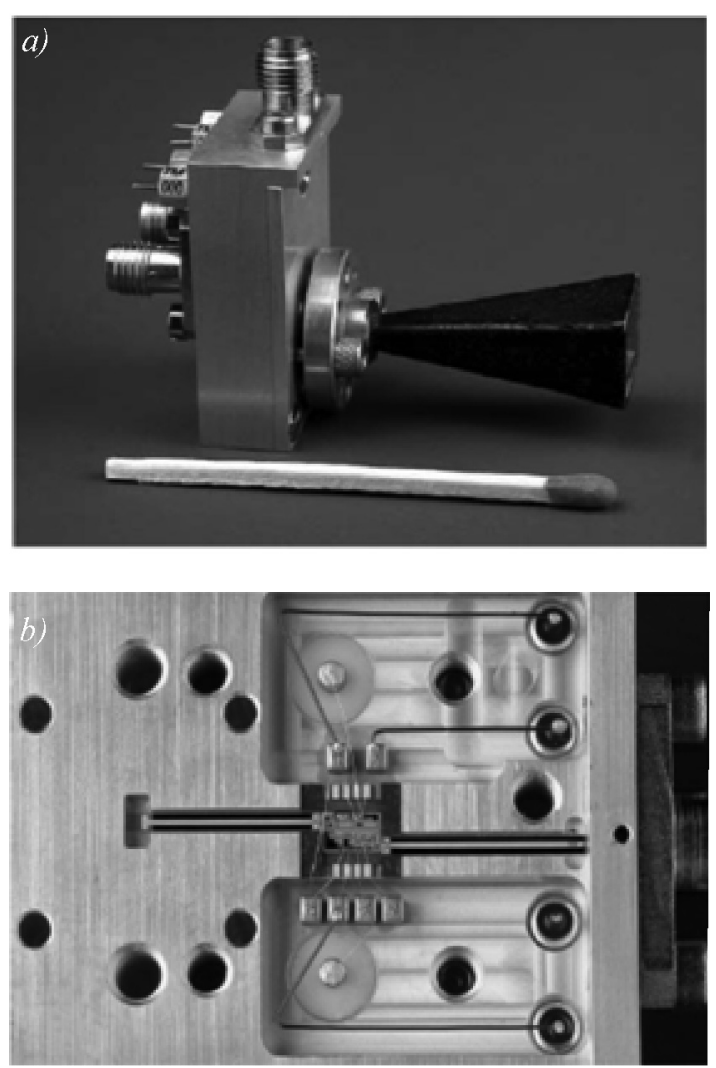

Fig. 6. Radar module for monitoring of GIT process, a) flanged horn antenna, b) inside view of the radar module

Fig. $7 \mathrm{~b}$ presents the result gained during an injection moulding test with gas assistance. The important process steps like the passage of the plastics melt and of the gas bubble over the 
position of the millimetre wave window could be found by abrupt changes of the measuring quantities amplitude, phase and frequency of the IF-signal. They could be identified unequivocally by comparison with a video movie taken during the test through an optical window.

The three measuring quantities can be combined to improve the validity of the method. Theoretical calculations using ANSYS FE code confirmed the findings and can be used in the future to optimize the measuring parameters like frequency or type of the millimetre wave window. Thus, the process sequence can be controlled in a quick and direct way.

\subsection{Tool-Integrated Ultrasonic Systems for Control of Cold Joining Processes}

In case of screw joints the pre-stressing force is significant for the joint strength and therefore, this force can be used to control the screwing process. Screw break or joint release after applied load are extreme consequences of an improper adjusted pre-stressing force. In order to control the screwing process, usually the torque moment or the angle of rotation is measured during the process. Both control variables could be incorrect in predicting the pre-stressing force due to the a priori unknown influence of friction loss between the screw head and support surface or between the screw thread and the mating thread.

It is well known that the screw elongation caused by pre-stressing can be determined by ultrasonic time-of-flight (TOF) measurements. Not only the increase of macroscopic screw length but also a decrease in ultrasonic velocity due to the acoustic-elastic effect result in a rising
TOF, when pre-stressing force is extended. Commercially available screwing control devices based on ultrasound measure the TOF in the screw only before and after but not during the screw drilling process. Afterwards the screw elongation or the pre-stressing force is determined by means of stored calibration tables.

Therefore, these conventional devices only allow the final inspection of the screw joint and if necessary the correcting of an improper prestressing force.

Measuring the ultrasonic TOF during screwing, as it has been described by Schneider et al. [5] allows a closed loop control of the process. For this purpose, the ultrasonic sensor and part of the electronics have to be integrated within the power screwdriver (see Fig. 8). Furthermore, the screw itself has to be applied with an ultrasonic coupling / reflection coating on its head / shank. This results in increased piece costs for the screws, impairing the market acceptance of the method. To overcome this drawback, the screwdriver can be equipped with a special coupling sheet in order to avoid a special pre-treatment of the screws.

Clinching, or press joining, is a highspeed mechanical fastening technique for point joining of sheet metal. It is a fast and simple single-step technique requiring no consumables or pre-drilled holes. Clinching can be used on coated and painted materials, and is suitable for joining dissimilar materials. During clinching, the sheets are squeezed between a punch and a die. Due to the high local pressure, the material start to yield, whereby material is expelled sideways forming an interlocking button (see Fig. 9a). It is this interlocking button that holds the sheets together. Currently, the clinching process is
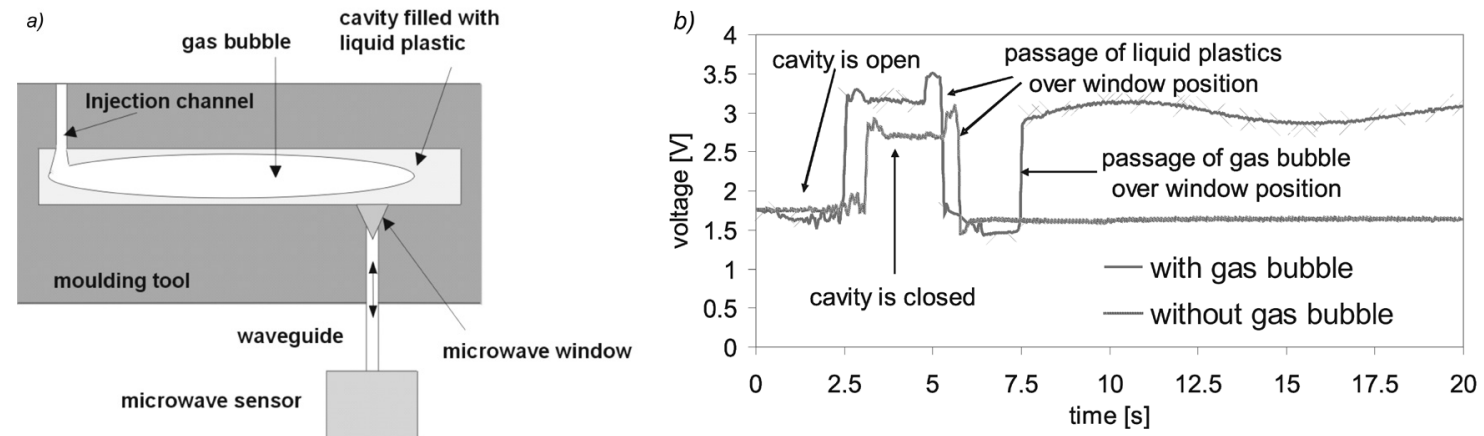

Fig. 7. GIT monitoring with radar, a) scheme GIT monitoring, b) radar measuring quantities versus time 
usually controlled by force-travel monitoring. The force-travel curve is controlled in order to follow a predefined target curve. However, this method is generally insensitive since local variations in undercut, neck or residual bottom thickness, which can considerably affect the joint strength, are hardly detectable in the force-travel curve.

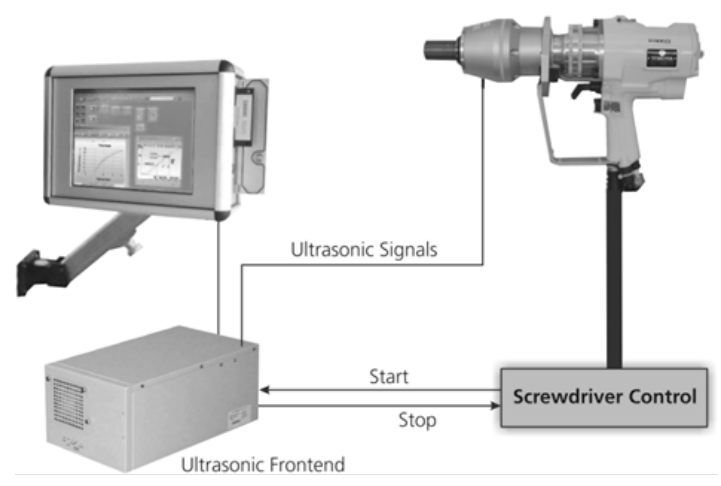

Fig. 8. Closed loop control of screwing process with screw nut integrated ultrasound

A new approach is to continuously measure the residual thickness of the punch-sided and the die-sided sheet with tool-integrated ultrasonic sensors (see Fig. 9b). Based on these measuring data, the residual bottom thickness and with it, the thickness of the undercut can be determined during the process. Determining this quality characteristics in-situ allows a reliable control of the clinching process.

\section{CONCLUSIONS}

Case studies have shown that NDT aided production provides a significant contribution in order to improve product quality, reduce scatter in properties, minimise scrap and improve process economy. Therefore, it is not surprising that the traditional tasks of NDT - preventive maintenance and off-line quality control - are more and more extended towards process integrated monitoring of quality characteristics and open / closed loop process control.

Modern NDT techniques used in the manufacturing industry have to follow the still strengthening trend to ever higher degrees of automation. In the future NDT will be an essential component of a more or less autonomously running production, assuring product and process quality with a minimum of man-machine interaction. Consequently, NDT techniques have to evolve from simple measuring machines to intelligent control systems. Today, the technologies to enhance the automation dregree and the "intelligence" of NDT techniques are available. Advanced miniaturized sensors with integrated signal evaluation techniques, fast electronics and algorithms for real-time data processing along with comprehensive information on the processing conditions and the properties and characteristics of the materials being processed, will provide new opportunities for efficient NDT-based real-time process monitoring and control in near future.

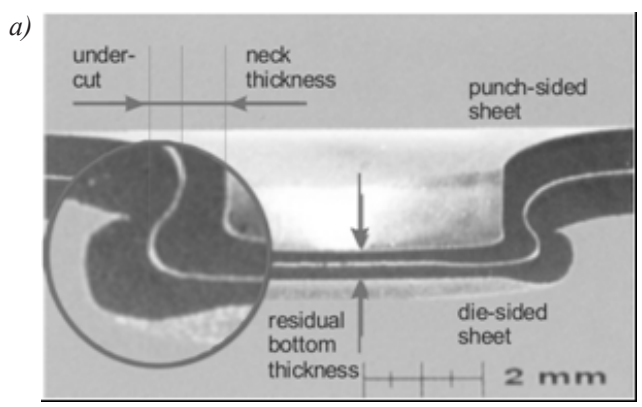

b)

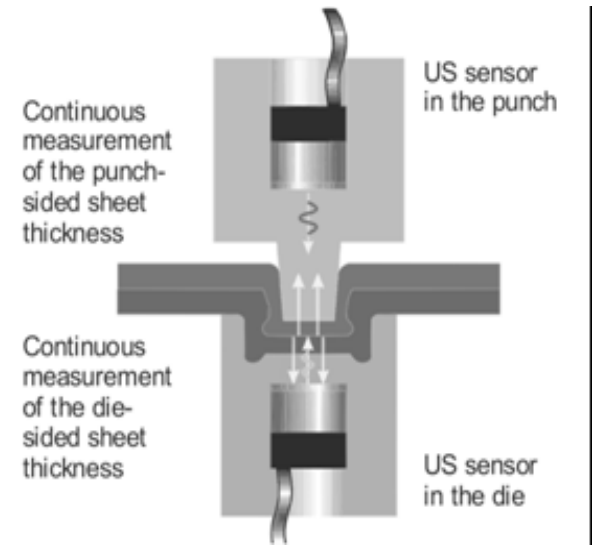

Fig. 9. Monitoring of clinch point quality with tool integrated ultrasound, a) quality characteristic of the clinch point, b) ultrasonic sensors integrated into punch and die

\section{REFERENCES}

[1] Kaierle, S., Abels, P., Fiedler, W., Mann, S., Regaard, B. (2008). OnlineQualitätssicherung für das Laserstrahlschweissen. Maschinenbau - Das Schweizer Industrie-Magazin, Jahres- 
Hauptausgabe MB-Revue, p. 132-135. (In German)

[2] Satoru, S. (2006). Sensing technology for the welding process. Welding International vol. 20, no. 3, p. 183-196.

[3] Waschkies, E. (1997). Process-integrated resistance spot welding testing using ultrasonic technique. Welding in the world. vol. 39, no. 6, p. 345-350.

[4] Dennison, A.V., Toncich, D.J., Masood S. (1997). Control and Process-Based Optimisation of Spot-Welding in Manufacturing Systems. International Journal of Advanced Manufacturing Technology, vol. 13, p. 256-263.

[5] Schneider, E., Herzer, H.R., Braunbach, K.H. (2005). Ultraschall-System zur on-line Bestimmung der Schraubenvorspannkraft und zur Schraubersteuerung, Proceedings of the DGZfP-Jahrestagung 2005, Berlin, Deutsche Gesellschaft für zerstörungsfreie Prüfung (DGZfP), V45. (In German)

[6] Guo, Y.B., Ammula, S.C. (2005). Real-time acoustic emission monitoring for surface damage in hard machining. International Journal of Machine Tools \& Manufacture vol. 45, p. 1622-1627.

[7] Chen, X., Griffin, J. (2007). Grinding Acoustic Emission Classification in Terms of Mechanical Behaviours. Key Engineering Materials, vol. 329, p. 15-20.

[8] Wolter, B., Kern, R., Kopp, H. (2005) Schleifwerkzeug mit integrierten mikromagnetischen Sensoren. European patent EP $1604782 \mathrm{Al}$.

[9] Altpeter, I., Kopp, M., Kröning, M., Milch, M., Schäffner, C., Behrens, B.A. (2006). Influences on the part quality in conventional deep drawing processes. Proceedings of the $9^{\text {th }}$ European Conference on Nondestructive Testing, Deutsche Gesellschaft für zerstörungsfreie Prüfung (DGZfP), Berlin, Fr.1.7.3.

[10] Dobmann, G., Altpeter, I., Wolter, B., Kern, R. (2008). Industrial applications of 3MA - micromagnetic multiparameter microstructure and stress analysis. Proceedings of the $5^{\text {th }}$ International Conference Structural Integrity of Welded Structures: ISCS 2007, Timisoara.

[11] Wolter, B., Kern, R., Schneider, E., Bucholtz, O.W., Hofmann, U., Meilland, P. (2005). Zerstörungsfreie Bestimmung von Qualitätsmerkmalen bei der Grobblechfertigung, Proceedings of the DGZfP-Jahrestagung, Berlin, Deutsche Gesellschaft für zerstörungsfreie Prüfung (DGZfP), V41. (In German)

[12] Sklarczyk, C., Surkov, A.S., Langenberg, K.J., Mayer, K. (2006). 94 GHz radar sensor for process control and imaging. Proceedings of the 9th European Conference on Nondestructive Testing, Deutsche Gesellschaft für zerstörungsfreie Prüfung (DGZfP), Berlin, We.2.8.4.

[13] Kloster, A., Kroening, M., Smorodinsky, J., Ustinov, V. (2006). A linear magnetic stray flux array based on GMR gradiometers. Electromagnetic Nondestructive Evaluation VII - eNDE, IOS Press, Amsterdam, p. 173179.

[14] Dobmann, G. (2007). Sensoren in der zerstörungsfreien Prüfung: Ziel ist die Charakterisierung eines Werkstoffes oder Bauteils, Sensors, p. 18-21. (In German)

[15] Bräuer, G., Bandorf, R., Biehl, S., Dietz, A., Lüthje, H., Vergöhel, M. (2006). Intelligente Schichten für denkende Oberflächen. Vakuum in Forschung und Praxis, vol. 18, no. 6, p. 25-29. (In German)

[16] Bulavinov, A., Kroening, M., Reddy, K.M., Ribeiro, J.G. (2007). Real-time quantitative ultrasonic inspection. Proc. of the $4^{\text {th }}$ PanAmerican Conference for Non-destructive Inspection, Buenoes Aires: Asociación Argentia de Ensayos No Destructivos y Estructurales (AAENDE), p. 69.

[17] Kroening, M., Ribeiro, J.G., Vidal, A. (2007). Progress in NDT system engineering through sensor physics and integrated efficient computing. Proc. of the $4^{\text {th }}$ PanAmerican Conference for Nondestructive Inspection, Buenoes Aires: Asociación Argentia de Ensayos No Destructivos y Estructurales (AAENDE), p. 70.

[18] Wolter, B., Dobmann, G. (2006). Micromagnetic Testing for Rolled Steel. Proceedings of the $9^{\text {th }}$ European Conference on Nondestructive Testing, Deutsche Gesellschaft für zerstörungsfreie Prüfung (DGZfP), Berlin, Th.3.7.1. 